\title{
Spatial Statistics and Age Structure of Leaf Cutting Ant Nests
}

\author{
Debora Maria Ferreira Canuto1, Sergio Furtado dos Reis ${ }^{2}$, Wesley Augusto Conde Godoy ${ }^{*}$ \\ ${ }^{1}$ Departamento de Entomologia e Acarologia, Escola Superior de Agricultura Luiz de Queiroz, Universidade de São Paulo, \\ Piracicaba, Brazil \\ ${ }^{2}$ Departamento de Biologia Animal, Universidade Estadual de Campinas, Campinas, Brazil \\ Email: *wacgodoy@usp.br
}

How to cite this paper: Canuto, D.M.F. dos Reis, S.F. and Godoy, W.A.C. (2019) Spatial Statistics and Age Structure of Leaf Cutting Ant Nests. Open Journal of Statistics, 9, 196-217.

https://doi.org/10.4236/ojs.2019.92015

Received: February 21, 2019

Accepted: April 8, 2019

Published: April 11, 2019

Copyright (c) 2019 by author(s) and Scientific Research Publishing Inc. This work is licensed under the Creative Commons Attribution International License (CC BY 4.0).

http://creativecommons.org/licenses/by/4.0/

(c) (i) Open Access

\begin{abstract}
In this study, we investigated the spatial aggregation of old and incipient nests of Atta sexdens rubropilosa by fitting Poisson and Negative binomial models to nest abundance data. Our aim is to analyse the distribution of ant nests in eucalypt regrowth, Cerrado and native forest fragment. We also investigated the correlation between nest abundance and climatic factors, as well as different nest ages. When comparing nests of different ages we observed an aggregated pattern for both old and incipient nests. On the other hand, analysing the distribution of nests separately, only taking into account the different areas and respective borders, old nests exhibited an aggregated pattern and incipient nests showed a random pattern, except for native forest with ants exhibiting only an aggregated pattern. The levels of aggregation changed in response to different areas and border gradients, with more external borders showing higher aggregation than more internal borders. Temperature was the variable showing the highest correlation with nest abundance and the correlation between nests of different ages was totally depending on the different areas.
\end{abstract}

\section{Keywords}

Spatial Statistics, Leaf Cutting Ant Nest Aggregation, Nest Age,

Forest Landscapes

\section{Introduction}

Spatial aggregation is a common pattern of distribution in leaf-cutting ant nests [1] [2]. Spatial aggregation is probably associated with the availability of resources, which are heterogeneously distributed within a given habitat [3]. As a consequence, ants generally follow patterns of distribution characterized by 
areas with high densities of nests and areas with no or few nests [1] [3]. This pattern of distribution is important in order for leaf-cutting ants to maintain populations in areas with a high potential for resource exploitation, while ensuring success in offspring production and dispersal to new areas with available resources [1]. The success of nests is also affected by their own temporal development [4]. Whereas old nests are extremely important for producing offspring, their existence is absolutely dependent on incipient nests; that is, nests built by queens shortly after the nuptial flight [5] [6]. Therefore, incipient nests are of prime importance for providing continuity of colonies and ensuring the introduction of leaf-cutting ants into new areas. Of course, both incipient and old nests provide continuity for leaf cutting ant colonies in different areas [5]. However, the success of leaf cutting ant continuity in each area depends essentially on the survival of incipient nests [5] [6]. Ant colony continuity also depends on the ability of ants to explore different areas [7].

Leaf-cutting ants are highly polyphagous [8] [9], therefore capable of cutting leaves from a wide variety of plants, including cultivated plants and planted forests [9]. Polyphagia requires intense movement of ants between different agricultural mosaics, planted forests, native forest, and different biomes [7] [10]. Movement ability differs though between castes. Workers only disperse over the ground, whereas queens reach greater distances because after the nuptial flight they disperse by flying to new areas in order to found new nests [9]. Movement of ants searching for resources probably incurs costs, which arise when workers travel long distances between nests and food sources [7]. By costs we mean the time and energy expended by workers transporting leaves and/or avoiding risks, such as predation by natural enemies [7]. Under these circumstances, the presence of nests near the edges of habitats containing resources should facilitate the acquisition of food substrate, explaining the common aggregation of nests near the edges [11].

Although we recognize spatial aggregation as a predominant pattern for leaf cutting ants in Eucalyptus forest, Cerrado, native forest and their respective edges to some extent, there are no systematic studies addressing the influence of nest age on the spatial aggregation of these insects, taking into account different types of vegetation. In this study, we investigated the spatial aggregation in different ages of $A$. sexdens rubropilosa nests, in areas of eucalypt regrowth, native forest fragment and Cerrado. Particularly, we are interested in understanding how ant nest age structure influences the spatial aggregation of colonies in different vegetation systems.

\section{Material and methods}

\subsection{Study Areas}

Data were collected in Itatinga, São Paulo, Brazil $\left(23^{\circ} 10^{\prime} \mathrm{S}, 48^{\circ} 40^{\prime} \mathrm{W}\right)$, recording the abundance of old and incipient leaf-cutting ant nests weekly, between March 2016 and February 2017 in three areas (Figure 1): eucalypt regrowth (29.77 ha), 


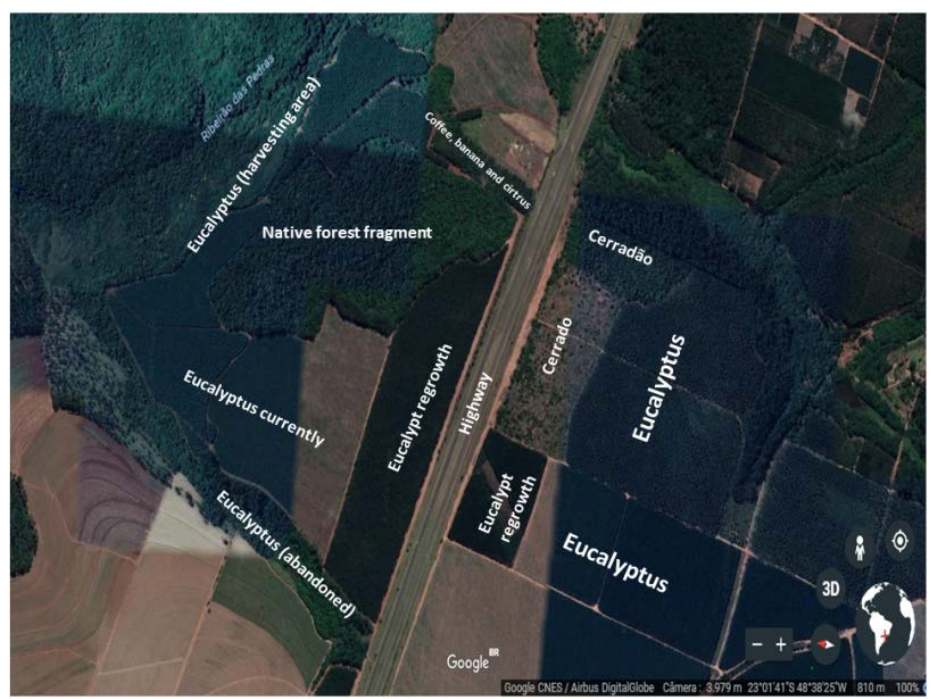

Figure 1. Experimental station in Itatinga, São Paulo, Brazil, where the spatial distribution of Atta sexdens rubropilosa was investigated in areas of eucalypt regrowth, Cerrado and a native forest fragment.

Cerrado (14.56 ha) and native forest fragment ( $44.37 \mathrm{ha})$. The distance between the eucalypt regrowth and Cerrado areas was $638 \mathrm{~m}$, between the Cerrado and native forest fragments $952 \mathrm{~m}$, and between the eucalypt regrowth and native forest areas $622 \mathrm{~m}$. The topography of the area is gentle rolling, with latosols and podzolic soils. The mean annual temperature is $20^{\circ} \mathrm{C}$, with a mean minimum of $3^{\circ} \mathrm{C}$ and maximum of $32^{\circ} \mathrm{C}$. The mean annual precipitation is $1350 \mathrm{~mm}$. The three areas received no insecticide applications during the study.

The eucalypt regrowth area contains Eucalyptus urograndis plantations, a hybrid clone between Eucalyptus grandis and Eucalyptus urophylla. The trees were 32 months old and the mean height was $7 \mathrm{~m}$. Eucalypt regrowth is the most widespread planting procedure among forest companies, which saves labour in establishing new forests. The study area is bounded by a highway, a fragment of native forest, a Eucalyptus plantation, and an abandoned Eucalyptus plantation (Figure 1). The Cerrado area is a savannah-like vegetation containing short, well-spaced trees, shrubs, and a sparse grass cover. It is bounded by a highway, Cerradão (tall transitional tropical forest), a Eucalyptus plantation and a eucalypt regrowth area (Figure 1). The native forest fragment is a remnant of natural vegetation, containing Seasonal Semideciduous Forest, Cerrado, wetlands, and an ecological transition zone, in addition to large areas with regenerating forest mixed with exotic species, mostly Eucalyptus spp. and Pinus spp. The area has not been logged or the plants removed since 1940. It is bounded by a Eucalyptus plantation that is periodically logged, a small area with coffee, banana and citrus plantings and eucalypt regrowth (Figure 1).

\subsection{Demarcation of Plots}

We set 207 plots per area, each measuring $21 \mathrm{~m} \times 24 \mathrm{~m}$, totalling 621 plots for all areas (Figure 2). 


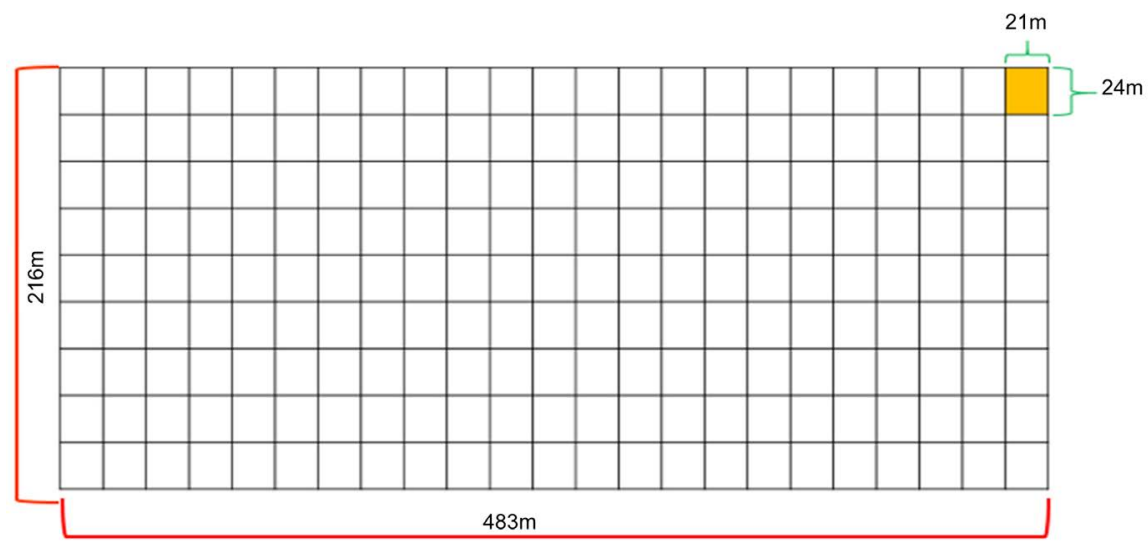

Figure 2. Experimental design for demarcation of plots.

\subsection{Abundance Estimates}

The abundance of old and incipient leaf-cutting ant nests was estimated for the three areas. To delimit each old nest we used the total area method, which is based on the volume of loose soil from each nest, as estimated by the product of the greatest length times the greatest width of loose soil [12]. The criterion for recording incipient nests was based on the presence of holes in the soil, with earth removed around them, which led to an underground chamber with a depth between 10 and $30 \mathrm{~cm}$ [6] [13]. A cylindrical tube measuring $35 \mathrm{~cm}$ in length by $2 \mathrm{~mm}$ in diameter was used to check the depth of the incipient nest.

\subsection{Spatial Distribution Statistics}

\subsubsection{Theoretical Foundation}

\section{1) Poisson distribution applied to ant nests}

The Poisson model describes count data following a random pattern of distribution with variance equal to mean [14]. Several processes, mainly in biological populations, show the variance increasing with the mean, often faster than linearly. The mean $(m)$ is obtained from the sample mean $(\bar{x})$ and it is determined as $n / N$, the arithmetic mean of the sample, where $n$ is the total number of ant nests and $N$ the total number of sampling units. The variance $\left(s^{2}\right)$ is

$$
s^{2}=\frac{\sum_{0}^{x}\left(x^{2} F_{x}\right)-\bar{x} n}{N-1},
$$

where, $F_{x}$ is the frequency of nests, having $x=0,1,2,3, \cdots, z$ nests. The Poisson distribution can be applied to the distribution of ant nests, assuming that the probability of finding $x$ nests in each sampling unit is $P(x)$, where $x=0,1,2,3, \cdots, z$ nests is given by Poisson distribution [14] [15] [16], expressed as

$$
P(x)=\frac{m^{x} \mathrm{e}^{-m}}{x !},
$$

where $m$ is the mean, the only parameter in the Poisson model, $e$ the base of the natural logarithm, and $x$ ! is the factorial of $x$. The parameter $m$ can be estimated by computing $\bar{X}$ from the data as the mean number of nests per sampling unit. 
It is possible to use $\bar{x}$ as an estimate of $m$, in order to obtain the probabilities of $x=0,1,2, \cdots, z$, nests per sampling unit, as follows:

$$
\begin{gathered}
P(0)=\mathrm{e}^{-\bar{x}} \\
P(1)=\bar{x}^{1} \frac{\mathrm{e}^{-\bar{x}}}{1 !} \\
P(2)=\bar{x}^{2} \frac{\mathrm{e}^{-\bar{x}}}{2 !} \\
P(3)=\bar{x}^{3} \frac{\mathrm{e}^{-\bar{x}}}{3 !} \\
\quad \vdots \\
P(z)=\bar{x}^{z} \frac{\mathrm{e}^{-\bar{x}}}{z !}
\end{gathered}
$$

As the Poisson model is based on probabilities, expected frequencies are required to be compared with observed frequencies, in order to verify the accuracy of the model. Then, each probability is multiplied by the total number $(N)$ of sampling units. $E(x)$ determines the expected frequencies of $x=0,1,2,3,4, \cdots, z$ ant nests per sampling unit. The expected frequencies of $x$ can be written as

$$
\begin{gathered}
E_{0}=N P(0) \\
E_{1}=N P(1) \\
E_{2}=N P(2) \\
E_{3}=N P(3) \\
\vdots \\
E_{z}=N P(z)
\end{gathered}
$$

The goodness-of-fit between the data and the Poisson model can be verified by using the Chi Square test, which determines how well the expected frequencies fit to observed frequencies.

\section{2) Negative binomial distribution applied to ant nests}

The negative binomial distribution is commonly used to describe clumped populations [14] [15], especially when two of the conditions associated with the Poisson model are not satisfied, i.e. a) each sampling unit has equal probability of having an individual and b) the occurrence of an individual in a sampling unit does not influence its occupancy by another. This scenario tends to result in populations exhibiting variance larger than the mean. There are two parameters in this distribution, $m$, here expressing the mean number of ant nests per sampling unit and $k$, the parameter estimating the degree of aggregation. Similarly to the Poisson model, the Negative binomial model takes into account the probability of finding $x$ ant nests in a sampling unit and, therefore, can also be viewed as a frequency distribution expressing the number of sampling units with $0,1,2,3, \cdots, z$ [14] [15] [16], written as 


$$
P(x)=\left(\frac{m}{m+k}\right)^{x}\left\{\frac{(k+x-1) !}{[x !(k-1)] !}\right\}\left[1+\left(\frac{m}{k}\right)\right]^{-k} .
$$

The parameter $k$ is the degree of aggregation, tending to zero at maximum aggregation. The estimate for $k$ can be obtained with the following iterative expression, using as a first iteration the value obtained from

$$
\hat{k}=\frac{\bar{x}^{2}}{s^{2}-\bar{x}} \text {. }
$$

to obtain

$$
\log _{10}\left(\frac{N}{N_{0}}\right)=\hat{k} \log _{10}\left[1+\left(\frac{\bar{x}}{\hat{k}}\right)\right],
$$

where, $N$ is the total number of sampling units in the sample and $N_{0}$ the number of sampling units with zero nests. With $\bar{X}$ and $k$ estimated, the probabilities of finding $X$ nests in a sampling unit can be computed as

$$
\begin{gathered}
P(0)=\left[\frac{\bar{x}}{(\bar{x}+\hat{k})}\right]^{0}\left[\frac{(\hat{k}+0-1) !}{0 !(\hat{k}-1) !}\left[1+\left(\frac{\bar{x}}{\hat{k}}\right)\right]^{-\hat{k}}=\left[1+\left(\frac{\bar{x}}{\hat{k}}\right)\right]^{-\hat{k}}\right. \\
P(1)=\left[\frac{\bar{x}}{(\bar{x}+\hat{k})}\right]^{1}\left[\frac{(\hat{k}+1-1) !}{1 !(\hat{k}-1) !}\right]\left[1+\left(\frac{\bar{x}}{\hat{k}}\right)\right]^{-\hat{k}}=\left[\frac{\bar{x}}{(\bar{x}+\hat{k})}\right]\left(\frac{\hat{k}}{1}\right) P(0) \\
P(2)=\left[\frac{\bar{x}}{(\bar{x}+\hat{k})}\right]^{2}\left[\frac{(\hat{k}+2-1) !}{2 !(\hat{k}-1) !}\right]\left[1+\left(\frac{\bar{x}}{\hat{k}}\right)\right]^{-\hat{k}}=\left[\frac{\bar{x}}{(\bar{x}+\hat{k})}\right]\left(\frac{\hat{k}+1}{2}\right) P(1) \\
P(z)=\left[\frac{\bar{x}}{(\bar{x}+\hat{k})}\right]^{z}\left[\frac{(\hat{k}+z-1) !}{z !(\hat{k}-1) !}\right]\left[1+\left(\frac{\bar{x}}{\hat{k}}\right)\right]^{-\hat{k}}=\left[\frac{\bar{x}}{(\bar{x}+\hat{k})}\right]\left(\frac{\hat{k}+z-1}{z}\right) P(z-1)
\end{gathered}
$$

The expected number of sampling units containing $x$ nests is obtained following the same steps in Equations (8) to (12) and the goodness-of-fit test follows the same procedure employed in the Poisson Model.

\subsubsection{Application}

The frequency distribution of $A$. sexdens rubropilosa nests was fitted to the negative binomial and Poisson distribution models in order to determine whether the spatio-temporal distribution of old and incipient nests followed an aggregated or random pattern. The number of nests per sampling unit was summarized as a frequency distribution, described as the number of plots with $0,1,2,3, \cdots, z$ nests. The $k$ parameter in the negative binomial distribution was used to estimate the spatial aggregation level of nests in case of data fitted to the negative binomial model. The value of $k$ indicates the highest aggregation when it is close to zero. $k$ was calculated by computing the maximum likelihood estimate for aggregation to obtain $\hat{k}$ as the best estimate for $k$ [14]. The parameter $k$ is estimated with 
successive iterations using the Equation (14), written as

$$
\log _{10}\left(\frac{N}{N_{0}}\right)=\hat{k} \log _{10}\left[1+\left(\frac{\bar{x}}{\hat{k}}\right)\right] \text {, }
$$

where, $N$ is the total number of sampling units, $N_{0}$ is the number of sampling units with zero individuals and $\hat{k}$ is the best estimate for $k$, computed from the maximum likelihood estimate. The fits of the negative binomial and Poisson models were tested with the Pearson $\chi^{2}$ statistic [14]. The chi-square test statistic is usually compared to a table of probabilities with a frequency class $c-2$ degree of freedom for Poisson and Negative binomial probability distributions. The distribution of ant nests was analysed taking into account two dimensions, time and space. To investigate the influence of time on the distribution patterns of nests, the weekly abundance of nests was sequentially examined for variation of values over time for old and incipient nests. Then, the Negative binomial and Poisson distributions were fitted to the observed frequency of nests in the 1st and 41th weeks and the distribution patterns at the two times were compared. To investigate the influence of space on nest distribution patterns, the frequency distribution in the three areas was also analysed with the two models, taking into account each total area and the respective area edges. Each area was analysed by subdividing it into five edges, from outside to the center, and classified as: external border, second, third, and fourth borders, and the central site (Figure 3).

The correlations between the total abundance of old and incipient nests, their temperature and relative humidity, as well as nests from different areas with different ages were analysed using Spearman's correlation, taking into account the non-normality of the data as evaluated with the Shapiro-Wilk test. All analyses were performed using R (RCore Team, 2013).

\section{Results}

The spatial distribution of $A$. sexdens rubropilosa differed markedly among the three areas investigated (Figures 4-6). Nests were most numerous inside the eucalypt regrowth area (Figure 4(a), Figure 4(b)), followed by the Cerrado (Figure 5(a), Figure 5(b)). However, in the Cerrado, nests were more displaced towards

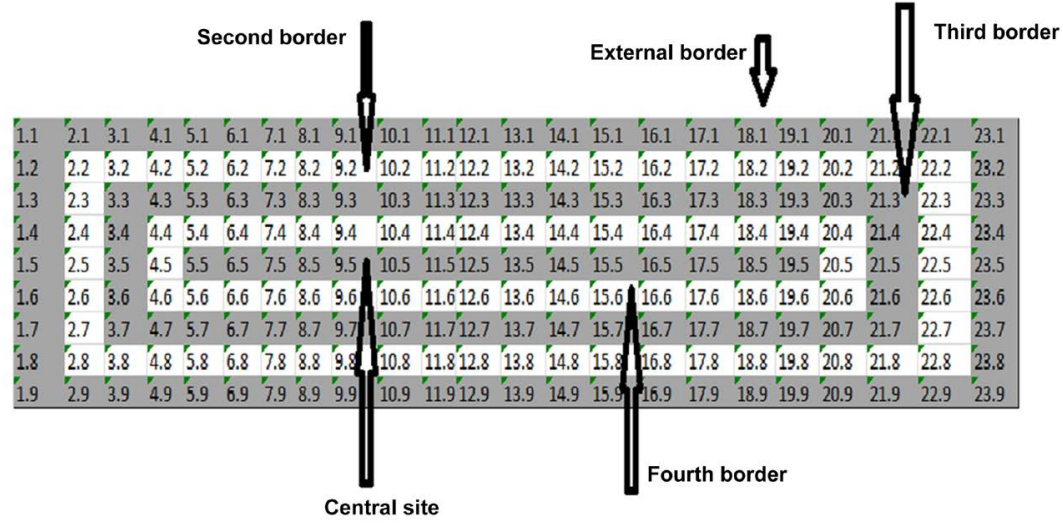

Figure 3. Design for the spatial analysis of borders. 


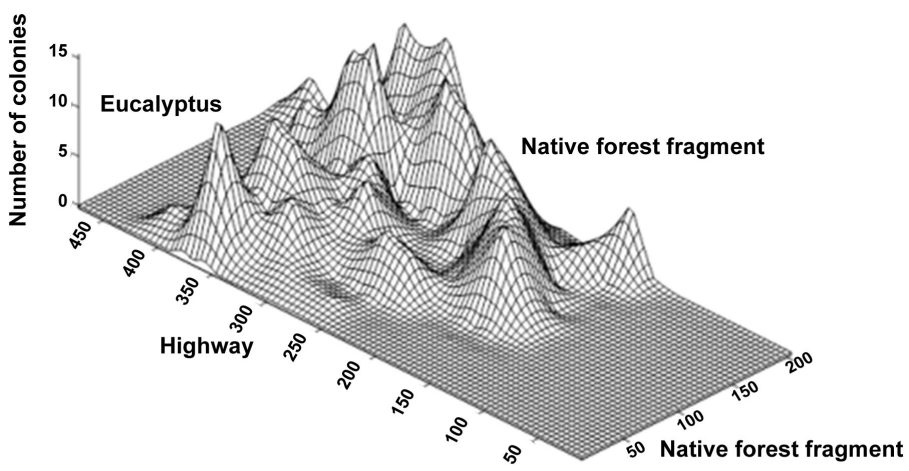

(a)

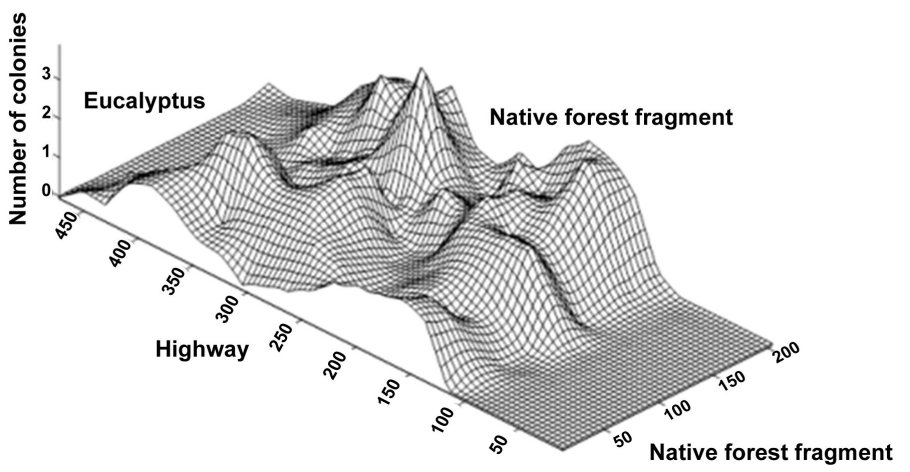

(b)

Figure 4. Spatial distribution of old (a) and incipient (b) nests of Atta sexdens rubropilo$s a$ in the Eucalypt regrowth area.

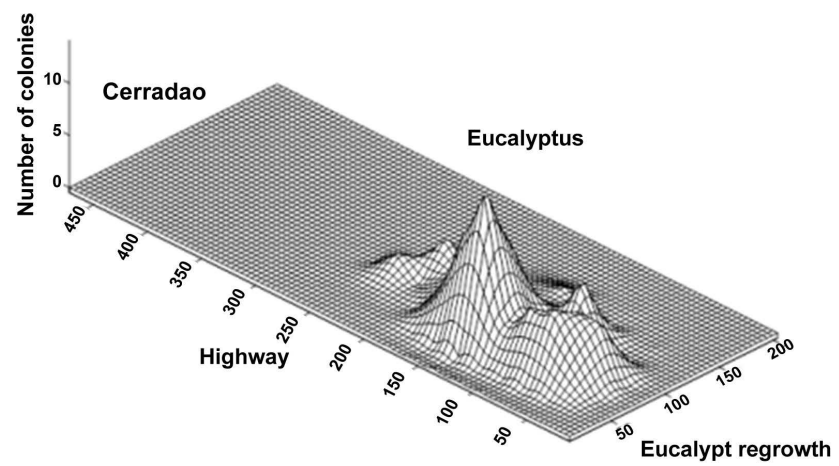

(a)

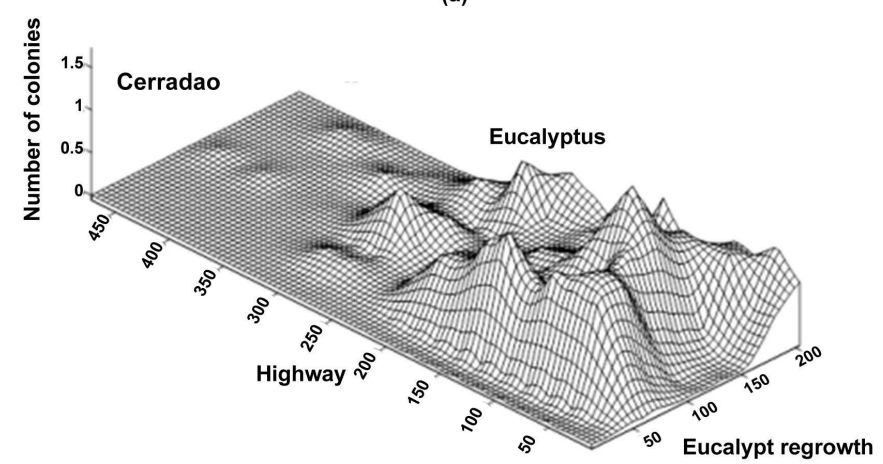

(b)

Figure 5. Spatial distribution of old (a) and incipient (b) nests of Atta sexdens rubropilosa in the Cerrado area. 
the eucalypt regrowth area, compared to other areas. In these areas, both old and incipient nests occupied more internal sites, but old nests were always present in higher densities. In contrast, in the native forest fragment, old nests appeared at the border with the Eucalyptus harvest area (Figure 6(a)) and incipient nests were close to the eucalypt regrowth and Eucalyptus plantation (Figure 6(b)).

The mean number of nests per hectare differed among the areas, with the eucalypt regrowth area having the highest abundance, 34.89 nests per hectare, followed by the native forest fragment, with 13.13/ha and the Cerrado with 7.76/ha. The spatial distribution of colonies, comparing old and incipient nests at two times, the 1st and 41st weeks, followed an aggregated pattern given by the Negative binomial model, with small differences in $k$ (Tables 1-3). Comparison among spatial distribution patterns, considering only space, showed an aggregated distribution for old nests, confirmed by data fitted to the Negative binomial distribution; and a random distribution for incipient nests, confirmed by data fitted to the Poisson distribution. The exception was the native forest nests, in which incipient nests also showed an aggregated distribution (Tables 4-6).

The analysis of spatial distribution patterns in old nests, taking into account the sequential borders from the most-external to the central site, indicated a decreasing level of aggregation (estimated by the $k$ parameter) from outside to the

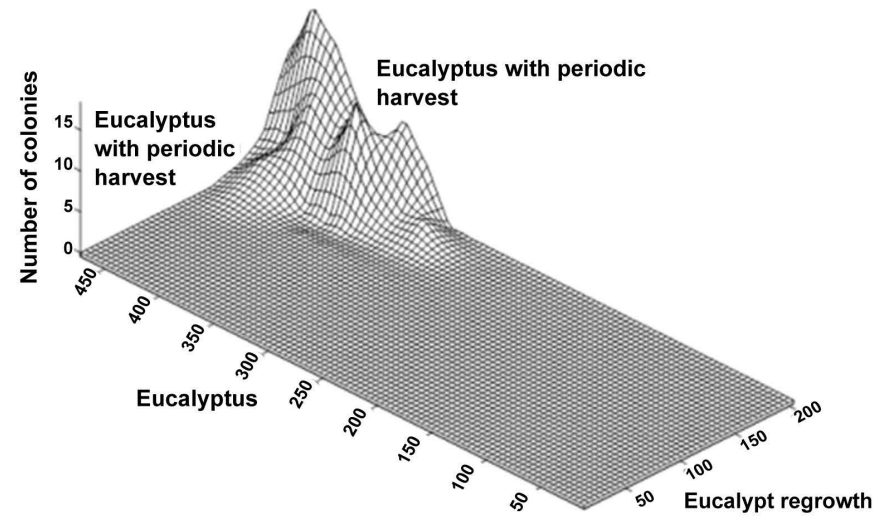

(a)

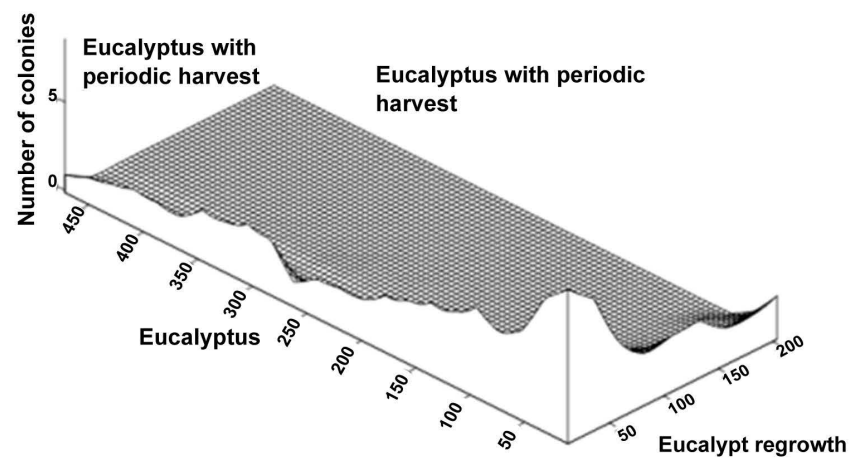

(b)

Figure 6. Spatial distribution of old (a) and incipient (b) nests of Atta sexdens rubropilo$s a$ in the Native forest fragment. 
Table 1. Spatial distribution patterns of old and incipient leaf-cutting ant nests in the eucalypt regrowth area, with observations in the 1 st and 41 st weeks.

\begin{tabular}{cccccc}
\hline \multicolumn{2}{c}{ Old nests } & \multicolumn{3}{c}{ Incipient nests } \\
\hline Estimates & 1st week & 41st week & Estimates & 1st week & 41 st week \\
\hline $\bar{x}$ & 1.7 & 1.88 & $\bar{x}$ & 1.15 & 0.39 \\
$s^{2}$ & 11.9 & 10.7 & $s^{2}$ & 5.01 & 1.13 \\
Fitted model & $\mathrm{NB}$ & $\mathrm{NB}$ & Fitted model: & $\mathrm{NB}$ & $\mathrm{NB}$ \\
$\chi^{2}$ & 20.1 & 21.9 & $\chi^{2}$ & 20.2 & 3.8 \\
$p<0.05, d f$ & 14 & 13 & $p<0.05, d f$ & 13 & 3 \\
$k$ & 0.23 & 0.33 & $k$ & 0.29 & 0.17 \\
\hline
\end{tabular}

$\bar{X}=$ mean, $s^{2}=$ variance, $d f=$ degrees of freedom, $k=$ aggregation parameter, $p<0.05$.

Table 2. Spatial distribution patterns of old and incipient leaf-cutting ant nests in the Cerrado area, with observations in the 1 st and 41 st weeks.

\begin{tabular}{cccccc}
\hline \multicolumn{2}{c}{ Old nests } & \multicolumn{3}{c}{ Incipient nests } \\
\hline Estimates & 1st week & 41 st week & Estimates & 1st week & 41 st week \\
\hline $\bar{x}$ & 0.44 & 0.55 & $\bar{x}$ & 0.64 & 0.06 \\
$s^{2}$ & 2.54 & 3.53 & $s^{2}$ & 3.11 & 0.07 \\
Fitted model & $\mathrm{NB}$ & $\mathrm{NB}$ & Fitted model & $\mathrm{NB}$ & $\mathrm{NB}$ \\
$\chi^{2}$ & 6.95 & 15 & $\chi^{2}$ & 14.2 & 0.03 \\
$p<0.05, d f$ & 11 & 13 & $p<0.05, d f$ & 12 & 2 \\
$k$ & 0.08 & 0.08 & $k$ & 0.14 & 0.17 \\
\hline
\end{tabular}

$\bar{X}=$ mean, $s^{2}=$ variance, $d f=$ degrees of freedom, $k=$ aggregation parameter, $p<0.05$.

Table 3. Spatial distribution patterns of old and incipient leaf-cutting ant nests in the Native forest fragment, with observations in the 1 st and 41 st weeks.

\begin{tabular}{cccccc}
\hline \multicolumn{2}{c}{ Old nests } & \multicolumn{3}{c}{ Incipient nests } \\
\hline Estimates & 1st week & 41 st week & Estimates & 1st week & 41 st week \\
\hline $\bar{X}$ & 0.54 & 0.70 & $\bar{x}$ & 0.67 & 0.69 \\
$s^{2}$ & 5.35 & 6.69 & $s^{2}$ & 6.69 & 6.64 \\
Fitted model & $\mathrm{NB}$ & $\mathrm{NB}$ & Fitted model & $\mathrm{NB}$ & $\mathrm{NB}$ \\
$\chi^{2}$ & 7.56 & 8.63 & $\chi^{2}$ & 12.21 & 1.42 \\
$p<0.05, d f$ & 16 & 16 & $p<0.05, d f$ & 10 & 14 \\
$k$ & 0.05 & 0.06 & $k$ & 0.21 & 0.07 \\
\hline
\end{tabular}

$\bar{X}=$ mean, $s^{2}=$ variance, $d f=$ degrees of freedom, $k$ = aggregation parameter, $p<0.05$.

Table 4. Spatial distribution patterns of old and incipient leaf-cutting ant nests in eucalypt regrowth area, taking into account the entire nest and borders from the outermost to the innermost.

\begin{tabular}{cc}
\hline \multicolumn{2}{c}{ Eucalypt regrowth } \\
\hline Old nests & Incipient nests \\
$\bar{x}=1.36$ & $\bar{x}=0.80$ \\
$s^{2}=8.48$ & $s^{2}=0.77$ \\
Fitted model Negative binomial & Fitted model Poisson \\
$\chi^{2}=4.2$ & $\chi^{2}=2.2$ \\
$p<0.05 d f=14$ & $p<0.01 d f=3$ \\
$k=0.22$ & \\
\hline
\end{tabular}




\section{Continued}

External border

$$
\begin{aligned}
\bar{X} & =1.33 \\
s^{2} & =11.8
\end{aligned}
$$

Fitted model Negative binomial

$$
\chi^{2}=4.61
$$$$
p<0.05 d f=9
$$

$$
k=0.14
$$$$
\bar{X}=1.01
$$$$
s^{2}=7.34
$$

Fitted model Negative binomial

$$
\chi^{2}=0.22
$$

$$
p<0.05 d f=11
$$

$$
k=0.14
$$

$$
\begin{aligned}
& \bar{X}=2.17 \\
& s^{2}=14.49 \\
& \chi^{2}=1.77
\end{aligned}
$$

Fitted model Negative binomial

$$
p<0.05 d f=132
$$$$
k=0.32
$$

$$
\begin{aligned}
\bar{x} & =1.91 \\
s^{2} & =9.84
\end{aligned}
$$

Fitted model Negative binomial

$$
\chi^{2}=0.49
$$$$
p<0.05 d f=8
$$

$$
k=0.38
$$

$$
\begin{aligned}
& \bar{X}=2.43 \\
& s^{2}=8.26
\end{aligned}
$$

Fitted model Negative binomial

$$
\begin{gathered}
\chi^{2}=0.17 \\
p<0.05 d f=6
\end{gathered}
$$$$
k=0.85
$$

$$
\begin{gathered}
\bar{X}=0.63 \\
s^{2}=0.78
\end{gathered}
$$

Fitted model Negative binomial

$$
\chi^{2}=4.12
$$

$p<0.05 d f=2$

$$
k=2.30
$$

Second

$$
\begin{gathered}
\bar{x}=0.6 \\
s^{2}=0.6
\end{gathered}
$$

Fitted model Poisson

$$
\chi^{2}=0.008
$$

$$
p<0.01 d f=2
$$

Third

$$
\begin{aligned}
& \bar{X}=0.89 \\
& s^{2}=0.79 \\
& \chi^{2}=0.32
\end{aligned}
$$

Fitted model Poisson

$$
p<0.01 d f=2
$$

Fourth

$$
\begin{aligned}
\bar{x} & =0.77 \\
s^{2} & =0.66
\end{aligned}
$$

Fitted model Poisson

$$
\chi^{2}=1.84
$$$$
p<0.01 d f=2
$$

Center

$$
\begin{gathered}
\bar{X}=1.01 \\
s^{2}=0.71
\end{gathered}
$$

Fitted model Poisson

$$
\chi^{2}=1.92
$$

$p<0.01 d f=2$

Table 5. Spatial distribution patterns of old and incipient leaf-cutting ant nests in Cerrado area, taking into account the entire nest and borders from the outermost to the innermost.

\begin{tabular}{cc} 
& Cerrado \\
\hline Old nests & Incipient nests \\
\hline $\bar{x}=0.45$ & $\bar{x}=0.20$ \\
\hline
\end{tabular}




\section{Continued}

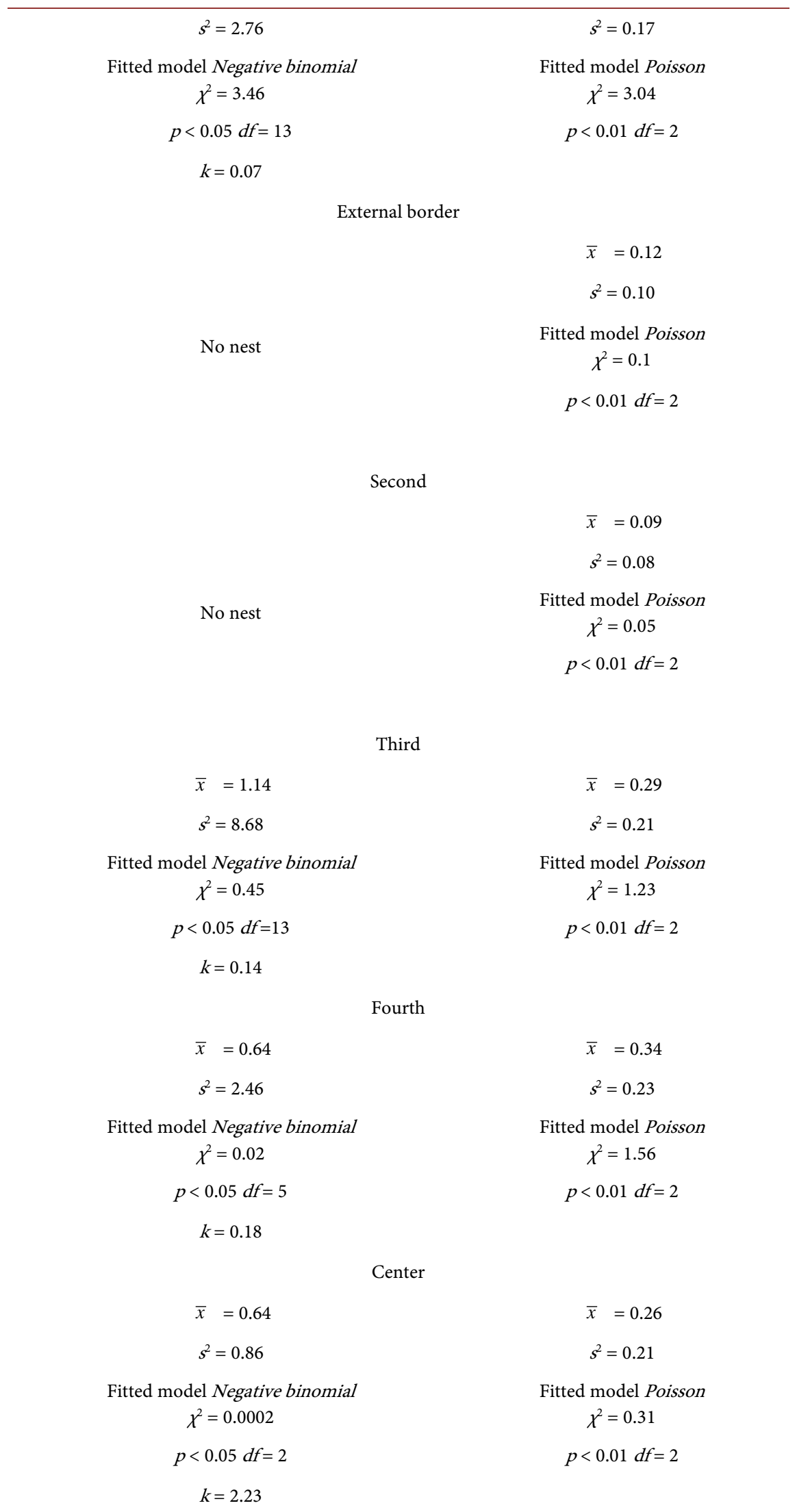


Table 6. Spatial distribution patterns of old and incipient leaf-cutting ant nests in Native forest fragment, taking into account the entire nest and borders from the outermost to the innermost.

\begin{tabular}{|c|c|}
\hline \multicolumn{2}{|c|}{ Native forest fragment } \\
\hline Old nests & Incipient nests \\
\hline $\bar{x}=0.61$ & $\bar{x}=0.09$ \\
\hline$s^{2}=6.18$ & $s^{2}=0.23$ \\
\hline $\begin{array}{l}\text { Fitted model Negative binomial } \\
\qquad \chi^{2}=3.18\end{array}$ & $\begin{array}{l}\text { Fitted model Negative binomial } \\
\qquad \chi^{2}=4.5\end{array}$ \\
\hline$p<0.05 d f=16$ & $p<0.01 d f=4$ \\
\hline$k=0.06$ & $k=0.24$ \\
\hline \multicolumn{2}{|c|}{ External border } \\
\hline $\bar{x}=0.61$ & $\bar{x}=0.64$ \\
\hline$s^{2}=6.18$ & $s^{2}=0.84$ \\
\hline $\begin{array}{l}\text { Fitted model Negative binomial } \\
\qquad \chi^{2}=1.64\end{array}$ & $\begin{array}{l}\text { Fitted model Negative binomial } \\
\qquad \chi^{2}=7.95\end{array}$ \\
\hline$p<0.05 d f=16$ & $p<0.01 d f=4$ \\
\hline$k=0.14$ & $k=2.11$ \\
\hline \multicolumn{2}{|c|}{ Second } \\
\hline $\bar{x}=0.92$ & $\bar{x}=0.24$ \\
\hline$s^{2}=6.62$ & $s^{2}=0.45$ \\
\hline $\begin{array}{l}\text { Fitted model Negative binomial } \\
\qquad \chi^{2}=0.24\end{array}$ & $\begin{array}{l}\text { Fitted model Negative binomial } \\
\qquad \chi^{2}=0.23\end{array}$ \\
\hline$p<0.05 d f=10$ & $p<0.01 d f=2$ \\
\hline$k=0.12$ & $k=0.46$ \\
\hline \multicolumn{2}{|c|}{ Third } \\
\hline $\begin{array}{c}\bar{x}=0.09 \\
s^{2}=0.23\end{array}$ & \multirow{4}{*}{ No nest } \\
\hline $\begin{array}{l}\text { Fitted model Negative binomial } \\
\qquad \chi^{2}=0.001\end{array}$ & \\
\hline$p<0.05 d f=2$ & \\
\hline$k=0.05$ & \\
\hline \multicolumn{2}{|c|}{ Fourth } \\
\hline No nest & No nest \\
\hline \multicolumn{2}{|c|}{ Center } \\
\hline No nest & No nest \\
\hline
\end{tabular}

inside the eucalypt regrowth area (Table 4). Because the incipient nests showed a random distribution, given by the Poisson distribution model (Table 4), they were omitted when comparing the $k$ parameter. Old nests in the Cerrado showed an aggregated distribution pattern, although the two outermost borders 
had no nests (Table 5). The central site showed a higher value for $k, 2.23$, indicating loss of aggregation from more-external borders to the central site (Table 5). Incipient nests in the Cerrado showed a random pattern of distribution for all borders (Table 5). Old nests in the native forest fragment showed an aggregated pattern; however, more-internal sites had no nests (Table 6). Incipient nests also showed an aggregated distribution, although the $k$ values were higher than for the old nests, with no nests in the more-central sites (Table 6).

There is a high correlation between the total number of nests and temperature in old nests in the eucalypt regrowth area (Spearman's rank correlation coefficient (rho) $=0.79, p<0.001)$. Relative humidity $(\mathrm{RH})$ was also significantly correlated $(p<0.02)$ with the total number of nests in the eucalypt regrowth area, with rho $=0.42$, indicating a moderate correlation. In the incipient nests, the correlation between the number of nests and temperature was significant $(p<$ $0.05)$, indicating a moderate correlation $(\mathrm{rho}=0.36)$; the correlation between the number of nests and relative humidity was not significant $(p>0.05)$. The correlation between old and incipient nests within the eucalypt regrowth area was also not significant $(p>0.05)$.

In old nests in the Cerrado, the correlation between temperature and the number of ant nests was also highly significant $(p<0.001)$, with rho $=0.8$; but the correlation between relative humidity and the number of nests was not significant $(p>0.05)$. In incipient nests, neither temperature nor relative humidity was correlated to the number of nests $(p>0.05)$. Comparison between old and incipient ant nests within the Cerrado indicated no significant correlation between them $(p>0.05)$. In the native forest fragment, the correlation between the number of old nests and temperature was highly significant $(p<0.001)$, with rho $=0.83$. Relative humidity was not correlated with the number of ant nests $(p>$ $0.05)$. With respect to incipient nests, both temperature and relative humidity were correlated with the number of nests $(p<0.001)$, with rho $=0.70$ and 0.47 .

Old and incipient nests of $A$. sexdens rubropilosa were significantly correlated with each other only in the native forest $(p<0.001)$, showing a high correlation, rho $=0.78$. The correlation analysis between nests in different areas indicated that old nests are significantly and highly correlated with each other in Cerrado versus eucalypt regrowth $(p<0.001$, rho $=0.86)$, eucalypt regrowth versus native forest fragment $(p<0.001$, rho $=0.91)$ and Cerrado versus native forest $(p<$ 0.001 , rho $=0.9$ ). Comparing incipient nests with each other between the different areas resulted in no significant correlation $(p>0.05)$. The combination old versus incipient nests (Table 7) in different areas showed a significant correlation in combinations of old nests in eucalypt regrowth versus incipient nests in native forest $(p<0.001$, rho $=0.79)$, old nests of Cerrado versus incipient nests of eucalypt regrowth $(p<0.04$, rho $=-0.35)$, and old nests of Cerrado versus incipient nests of native forest $(p<0.001$, rho $=0.69)$. The correlations between old nests of eucalypt regrowth versus incipient nests of Cerrado, incipient nests of eucalypt regrowth versus old nests of native forest, and incipient nests of Cerrado versus old nests of native forest were not significant $(p>0.05)$. 
Table 7. Correlations for old and incipient ant nests in combinations between areas.

\begin{tabular}{|c|c|c|}
\hline \multicolumn{3}{|c|}{ Old with old } \\
\hline Combination between areas & Correlation result & Correlation coefficient \\
\hline eucalypt regrowth $\times$ Cerrado & Yes & $0.86(p<0.001)$ \\
\hline eucalypt regrowth $\times$ native forest & Yes & $0.91(p<0.001)$ \\
\hline native forest $\times$ Cerrado & Yes & $0.90(p<0.001)$ \\
\hline \multicolumn{3}{|c|}{ Incipient with incipient } \\
\hline Combination between areas & Correlation result & Correlation coefficient \\
\hline eucalypt regrowth $\times$ Cerrado & No & Ns (non-significant) \\
\hline eucalypt regrowth $\times$ native forest & No & Ns \\
\hline native forest $\times$ Cerrado & No & Ns \\
\hline \multicolumn{3}{|c|}{ Old with incipient } \\
\hline Combination between areas & Correlation result & Correlation coefficient \\
\hline eucalypt regrowth (old) $\times$ Cerrado (incipient) & No & Ns \\
\hline eucalypt regrowth $($ old $) \times$ native forest (incipient) & Yes & $0.79(p<0.001)$ \\
\hline native forest (old) $\times$ Cerrado (incipient) & No & Ns \\
\hline eucalypt regrowth (incipient) $\times$ Cerrado (old) & Yes & $-0.35(p<0.001)$ \\
\hline eucalypt regrowth (incipient) $\times$ native forest $($ old $)$ & No & Ns \\
\hline native forest (incipient) $\times$ Cerrado (old) & Yes & $0.69(p<0.001)$ \\
\hline
\end{tabular}

\section{Discussion}

Our results suggest that the spatial distribution of $A$. sexdens rubropilosa differs between the three areas investigated, with high density of nests inside the eucalypt regrowth and Cerrado, and a concentration of nests with lower densities at the border of native forest. Three spatial patterns of nest distribution can be observed in Figures 4-6. High densities inside the eucalypt regrowth, high densities away from the center towards the Eucalyptus in Cerrado, and nests completely concentrated at the borders in native forest. The eucalypt regrowth had the highest abundance of leaf-cutting ant nests.

The high numbers of leaf-cutting ants in Eucalyptus areas results in significant economic damage to the forestry sector [2]. Damage is easily visible and documented in the Eucalyptus forest, but is difficult to be perceived in the Cerrado [17], although the presence of nests is extensively documented in Cerrado surveys [17] [18]. Nests in Cerrado bring significant temporary resource for ants waiting for new colonisations in Eucalyptus areas, mainly in the case of neighboring areas. Under these conditions, the Cerrado can act as a refuge area for ants during the Eucalyptus harvest period, as previously verified for other insect species [19] [20]. Refuge areas have been intensely discussed in different contexts [19] [20], but not as alternative resources for ants facing the temporary absence of Eucalyptus as a consequence of harvesting.

Brazilian Eucalyptus plantations have rapid periods of harvesting in response 
to the growing demand for younger trees, thanks to intense selection of clones [21]. This demand results in the systematic rotation of trees in Eucalyptus areas, a reason why probably ant nests are aggregated in borders, especially between native forest and Eucalyptus plantations or Cerrado and Eucalyptus plantations. With the rotation of trees, the number of leaves available to supply ant nests decreases drastically and incipient nests can be rapidly eliminated, increasing the risk that ant populations will fail to persist. However, old nests easily persist to the next Eucalyptus planting, using other resources. A variety of resources can be obtained by workers living in old nests because they are capable of foraging for much longer distances than workers in incipient nests [22].

Cultivated plants explored by the same organism raise questions about resource choice. Plant choice in ants is important and can influence nest success, especially in cases of cultivated plant [23]. There is evidence that the continuous availability of specific plants influences ant preference [23], and this trend can be important for monocultures. Various factors are likely responsible for plant preference in leaf-cutting ants, and chemical communication is certainly involved in choice behaviour [10] [24] [25]. Particularly in Eucalyptus, essential oils are likely important as allelochemicals in determining the ants' choice of plants to attack [26]. Although we do not know the exact cause of the ants' attraction to Eucalyptus, our results clearly indicate a significant influence of this vegetation type on the distribution of $A$. sexdens rubropilosa. The mean number of ant nests per hectare was 34.89 in eucalypt regrowth, 13.13 in Native forest and 7.76 in Cerrado areas. This result very likely reflects the attraction of ants to Eucalyptus leaves by ants.

The results of comparisons between nests of different ages suggest that colonies of 1st and 41st weeks show the same distribution pattern. Both old and incipient nests showed aggregated distributions. Nests of different ages are expected to exhibit similar patterns of distribution, at least to some extent. The resource can be shared by incipient and aging nests, probably based on recent experiences of successful nests. When queens start new nests after the mating flight, several factors supposedly affect their choice of the best sites for successful colonies. As successful colonies are commonly found close to each other, it can be assumed that favourable local conditions contribute the high degree of aggregation commonly observed.

Soares \& Schoereder [27] proposed three factors that are probably associated with nest aggregation, after investigating nest distribution in Brachymyrmex sp., Hypoponera sp., Pheidole sp. and Solenopsis sp. Aggregation of suitable microhabitats, colony budding, and mutualistic interactions could account for clumping of nests in tropical forests [27]. No studies have yet examined these factors for leaf-cutting ant nests. The combination of these factors with availability of potentially favourable sites for the successful development of initial colonies could, at least partially, explain the high potential of nests of leaf-cutting ant success in these areas. 
Comparison among distribution patterns considering only space found an aggregated distribution for old nests and a random distribution for incipient nests. Aggregated patterns have been observed in previous studies designed to evaluate the spatial distribution of leaf-cutting ants in forest areas and Cerrado [17] [18]. Our experimental design compared different areas and ant nests, showing that old nests are much more prone to be highly aggregated than are the incipient nests, which showed a random pattern in most cases. These results are probably associated with the density distribution of ants and the frequency of empty sites. Therefore, the distribution of nests is totally associated with resource distribution [3] [28]. The distribution of resources within areas determines distribution of ants, which probably develop strategies to reach food items [28] [29]. Foraging strategies are certainly linked to food-resource availability, a factor closely associated with different types of vegetation [30]. Resource availability probably influences much more incipient nests than old nests. Incipient nests are highly transitory compared to older ones, and consequently highly susceptible to local extinction. This could explain the random distribution observed in incipient nests, characterized by no aggregation and low densities.

Several environmental factors influence the establishment of incipient nests in different areas, besides the physiological and behavioural aspects that may affect the placement of incipient nests, for example, the initial effort by queens cultivating the symbiotic fungi by themselves [31]. This action requires high consumption of energy reserves and also rejection of harmful substrates for the symbiotic fungi [31]. These aspects are expected to increase the costs for queens to disperse after the mating flight [6] [31]. In addition, queens search for suitable sites to install nests, travelling different distances at a significant risk to their survival [32]. This reduces the viability of queens, influencing the density of nests, which could contribute to the low aggregation level of incipient nests.

The gradient of borders analysis showed significant influences of edges on ant nest distribution, with the more-external borders indicating more aggregated nests than the colonies placed more internally. External borders in which Eucalyptus was present concentrated many more ant nests than the more-internal areas, especially in the native forest fragment, followed by Cerrado. Some studies have found an increased density of ant nests near forest edges [33] [34]. Nest distribution patterns in the borders followed the general patterns observed for the total area, with few exceptions, as observed in the most-external border for incipient nests in eucalypt regrowth. However, particularly in this case, we observed a higher value of $k, 2.3$, suggesting that although data were fitted to the Negative binomial model, the level of aggregation was lower than in other borders. These results are probably associated with the lower number of sampling units with zero nests found in this border. In the Cerrado, the two more-external borders had zero colonies, and in the native forest fragment five more-internal borders had zero nests, both old and initial nests. Of the three areas, the eucalypt regrowth area had the fewest empty sites. This result can be explained by the af- 
finity of A. sexdens rubropilosa with Eucalyptus trees, as seen in the wide occupation of sites.

Temperature was more correlated with the abundance of old or incipient nests than with the relative humidity. Although both variables are highly important for leaf-cutting ant nests, temperature seems to be the most critical climatic variable [35] [36]. Some evidence indicates that temperature regulation may help to control humidity and prevent dehydration of the symbiont fungi and immatures [36]. Ants are also able to transfer nests in response to high temperatures [37], and on a wider scale, air temperature influences their geographic distribution patterns [38]. Old and incipient nests of $A$. sexdens rubropilosa were significantly and highly correlated with each other only in the native forest. This result could be explained by the proximity between nests. Nests were present only in the borders of the native forest fragment, due to the proximity to the neighbouring Eucalyptus plantation. The preference of leaf-cutting ants for Eucalyptus explains the high density of nests in this area and the low abundance of nests throughout the native forest. Native forests have much more heterogeneous vegetation compared to monoculture, which significantly influences the distribution of nests [39].

Incipient nests showed no significant difference among areas. This result could be explained by the homogeneity in terms of nest failure. Incipient nests contain a low abundance and diversity of castes, with a heavy load of tasks on the queen [40]. The founding stage, that is, the incipient nests, is certainly the stage of highest vulnerability to predation, parasitism, and competition. This is especially so for leaf-cutting ants because these ants require symbiotic fungi to establish new nests [31]. This condition is very different from that of old nests, which generally provide better conditions for ants, with tasks distributed among different castes, lightening much of the queen's load and mitigating the risks for nest establishment [13].

The correlation combining old versus incipient nests from different areas was significant. The result suggests an important role for old nests in the eucalypt regrowth area, probably providing offspring and initial resources for new nests in the native forest. Old nests in the Cerrado provide the same for the eucalypt regrowth area, and old nests in the Cerrado also contribute incipient nests to native forest. All these have areas next to each other or borders with vegetation with a high potential for exploitation by leaf-cutting ants. The edge effect seems to play an important role in the success of leaf-cutting ants [13] [41]. In particular, in this study the results clearly show the role of these areas as a refuge for ants in the absence or low density of Eucalyptus. Our results showed higher densities of ants in eucalypt regrowth compared with native forest and Cerrado areas, and a higher density of nests close to borders than in internal areas, mainly in areas neighbouring Eucalyptus plantations. The presence of nests in the native forest edge reflects the influence of Eucalyptus on ant abundance in this area. 


\section{Conclusion}

There is significant influence of vegetation on the spatial distribution of ant nests with different ages, with native forest having the highest concentration of nests at the borders. There is also a significant correlation between old and incipient nests, but the type of vegetation may change the levels of correlation.

\section{Acknowledgements}

We thank CAPES for granting a Ph.D. scholarship to the first author. WACG is supported by a research fellowship from the Brazilian National Council for Scientific and Technological Development (CNPq). Thanks are due to staff of the Itatinga Forest Experimental Station, for all field support for the project. We thank Janet Reid for revising the English text.

\section{Conflicts of Interest}

The authors declare no conflicts of interest regarding the publication of this paper.

\section{References}

[1] Ramos, V., Forti, L., Andrade, A., Noronha, N. and Camargo, R. (2008) Density and Spatial Distribution of Atta sexdens rubropilosa and Atta laevigata Colonies (Hym., Formicidae) in Eucalyptus spp. Forests. Sociobiology, 51, 775-781.

[2] Zanetti, R., Zanuncio, J., Santos, J., da Silva, W., Ribeiro, G. and Lemes, P. (2014) An Overview of Integrated Management of Leaf-Cutting Ants (Hymenoptera: Formicidae) in Brazilian Forest Plantations. Forests, 5, 439-454. https://doi.org/10.3390/f5030439

[3] Camargo, R.S., Fonseca, J.A., Lopes, J.F.S. and Forti, L.C. (2013) Influência do ambiente no desenvolvimento de colônias iniciais de formigas cortadeiras (Atta sexdens rubropilosa). Ciência Rural, 43, 1375-1380. https://doi.org/10.1590/S0103-84782013000800006

[4] Keiser, C., Vojvodic, S., Butler, I., Sartain, E., Rudolf, V. and Saltz, J. (2018) Queen Presence Mediates the Relationship between Collective Behaviour and Disease Susceptibility in Ant Colonies. Journal of Animal Ecology, 87, 379-387. https://doi.org/10.1111/1365-2656.12696

[5] Cardoso, S., Forti, L., Nagamoto, N. and Camargo, R. (2014) First-Year Nest Growth in the Leaf-Cutting Ants Atta bisphaerica and Atta sexdens rubropilosa. Sociobiology, 61, 243-249. https://doi.org/10.13102/sociobiology.v61i3.243-249

[6] Camargo, R., Forti, L., Matos, C., Caldato, N. and Fonseca, O. (2016) Is the Initial Nest depth Adapted to Favorable Conditions for the Incipient Colony in Leaf-Cutting Ants? Sociobiology, 63, 792-799.

[7] Cibils-Martina, L., Elizalde, L. and Farji-Brener, A.G. (2017) Traffic Rules around the Corner: Walking of Leaf-Cutting Ants at Branching Points in Trunk Trails. Insect Sociaux, 64, 549-555. https://doi.org/10.1007/s00040-017-0576-5

[8] Herz, H., Holldobler, B. and Roces, F. (2008) Delayed Rejection in a Leaf-Cutting Ant after Foraging on Plants Unsuitable for the Symbiotic Fungus. Behavioral Ecology, 19, 575-582. https://doi.org/10.1093/beheco/arn016

[9] Wirth, R., Herz, H., Ryel, R.J., Beyschlag, W. and Hölldobler, B. (2003) Herbivory of 
Leaf-Cutting Ants. Springer-Verlag, Berlin.

[10] Rockwood, L.L. and Hubbell, S.P. (1987) Host-Plant Selection, Diet Diversity, and Optimal Foraging in a Tropical Leafcutting Ant. Oecologia, 74, 55-61. https://doi.org/10.1007/BF00377345

[11] Leal, I., Wirth, R. and Tabarelli, M. (2014) The Multiple Impacts of Leaf-Cutting Ants and Their Novel Ecological Role in Human-Modified Neotropical Forests. Biotropica, 46, 516-528. https://doi.org/10.1111/btp.12126

[12] Grandeza, L.A.O., Moraes, J.C. and Zanetti, R. (1999) Estimativa do Crescimento Externo de Ninhos de Atta sexdens rubropilosa Forel e Atta laevigata (F. Smith) (Hymenoptera: Formicidae) em Áreas de Reflorestamento com Eucalipto. Anais da Sociedade Entomologica do Brasil, 28, 59-64. https://doi.org/10.1590/S0301-80591999000100006

[13] Holldobler, B. and Wilson, E.O. (2009) The Super Organism: The Beauty, Elegance, and Strangeness of Insect Societies. W. W. Norton \& Company, New York.

[14] Crawley, M.J. (2013) The R book. John Wiley \& Sons Ltd., Chichester.

[15] Gowda, D.M. (2011) Probability Models to Study the Spatial Pattern, Abundance and Diversity of Tree Species. Conference on Applied Statistics in Agriculture, The Kansas State University, Manhattan, KS, 1-3 May 2011, 82-95.

https://doi.org/10.4148/2475-7772.1048

[16] Sokal, R.R. and Rohlf, J. (2012) Biometry. 4th Edition, W.H. Freeman and Company, New York.

[17] Perin, M.A.A. and Guimarães, J.F. (2012) Efeitos dos ninhos de Atta laevigata (Fr. Smith, 1858) (Hymenoptera: Formicidae) sobre a vegetação do cerrado. Revista Arvore, 36, 463-470. https://doi.org/10.1590/S0100-67622012000300008

[18] Costa, A. and Vieira-Neto, E. (2016) Species Turnover Regulates Leaf-Cutter Ant Densities in Environmental Gradients across the Brazilian Cerrado. Journal of Applied Entomology, 140, 474-478. https://doi.org/10.1111/jen.12277

[19] Vasconcellos, A., Andreazze, R., Almeida, A.M., Araujo, H.F.P., Oliveira, E.S. and Oliveira, U. (2010) Seasonality of Insects in the Semi-Arid Caatinga of Northeastern Brazil. Revista Brasileira de Entomologia, 54, 471-476.

https://doi.org/10.1590/S0085-56262010000300019

[20] Harterreiten-Souza, E.S., Togni, P.H.B., Pires, C.S.S. and Sujii, E.R. (2014) The Role of Integrating Agroforestry and Vegetable Planting in Structuring Communities of Herbivorous Insects and Their Natural Enemies in the Neotropical Region. Agroforest Systems, 88, 205-219. https://doi.org/10.1007/s10457-013-9666-1

[21] Morais, P., Longue, D., Colodette, J., Morais, E. and Jardim, C. (2017) Influence of Clone Harvesting Age of Eucalyptus grandis and Hybrids of Eucalyptus Grandis $\times$ Eucalyptus urophylla in the Wood Chemical Composition and in Kraft Pulpability. Ciência Florestal, 27, 237-248. https://doi.org/10.5902/1980509826462

[22] Giehr, J., Heinze, J. and Schrempf, A. (2017) Group Demography Affects Ant Colony Performance and Individual Speed of Queen and Worker Aging. Biomed Central Evolutionary Biology, 17, 173-180. https://doi.org/10.1186/s12862-017-1026-8

[23] Camargo, R., Forti, L., Lopes, J. and de Matos, C. (2008) Growth of Populations and the Fungus Garden of Atta sexdens rubropilosa (Hymenoptera, Formicidae) Response to Foraged Substrates. Sociobiology, 52, 633-643.

[24] Arenas, A. and Roces, F. (2017) Avoidance of Plants Unsuitable for the Symbiotic Fungus in Leaf-Cutting Ants: Learning Can Take Place Entirely at the Colony Dump. PLoS ONE, 12, e0171388. https://doi.org/10.1371/journal.pone.0171388 
[25] Rockwood, L. (1976) Plant Selection and Foraging Patterns in 2 Species of Leaf-Cutting Ants (Atta). Ecology, 57, 48-61. https://doi.org/10.2307/1936397

[26] Batista-Pereira, L., Fernandes, J., da Silva, M., Vieira, P., Bueno, O. and Correa, A. (2006) Electrophysiological Responses of Atta sexdens rubropilosa Workers to Essential Oils of Eucalyptus and Its Chemical Composition. Zeitschrift für Naturforschung C: A Journal of Biosciences, 61, 749-755. https://doi.org/10.1515/znc-2006-9-1023

[27] Soares, S. and Schoereder, J. (2001) Ant-Nest Distribution in a Remnant of Tropical Rainforest in Southeastern Brazil. Insectes Sociaux, 48, 280-286. https://doi.org/10.1007/PL00001778

[28] Lanan, M. (2014) Spatiotemporal Resource Distribution and Foraging Strategies of Ants (Hymenoptera: Formicidae). Myrmecology News, 20, 53-70.

[29] Gordon, D.M. (2019) The Ecology of Collective Behavior in Ants. Annual Review of Entomology, 64, 35-50. https://doi.org/10.1146/annurev-ento-011118-111923

[30] Sousa-Souto, L., Schoereder, J. and Lima, E. (2008) Why Do Leaf-Cutting Ants (Hymenoptera: Formicidae) Change Their Foraging Pattern? Sociobiology, 52, 645-654.

[31] Fernández-Marín, H., Zimmerman, J.K. and Wcislo, W.T. (2004) Ecological Traits and Evolutionary Sequence of Nest Establishment in Fungus-Growing Ants (Hymenoptera, Formicidae, Attini). Biological Journal of the Linnean Society, 81, 39-48. https://doi.org/10.1111/j.1095-8312.2004.00268.x

[32] Robinson, E. (2014) Polydomy: The Organisation and Adaptive Function of Complex Nest Systems in Ants. Current Opinion in Insect Science, 5, 37-43. https://doi.org/10.1016/j.cois.2014.09.002

[33] Dohm, C., Leal, I.R., Tabarelli, M., Meyer, S.T. and Wirth, R. (2011) Leaf-Cutting Ants Proliferate in the Amazon: An Expected Response to Forest Edge? Journal of Tropical Ecology, 27, 645-649.

[34] Siqueira, F., Ribeiro-Neto, J., Tabarelli, M., Andersen, A., Wirth, R. and Leal, I. (2017) Leaf-Cutting Ant Populations Profit from Human Disturbances in Tropical Dry Forest in Brazil. Journal of Tropical Ecology, 33, 337-344. https://doi.org/10.1017/S0266467417000311

[35] Bollazzi, M. and Roces, F. (2010) Leaf-Cutting Ant Workers (Acromyrmex heyeri) Trade off Nest Thermoregulation for Humidity Control. Journal of Ethology, 28, 399-403. https://doi.org/10.1007/s10164-010-0207-3

[36] Bollazzi, M., Kronenbitter, J. and Roces, F. (2008) Soil Temperature, Digging Behaviour, and the Adaptive Value of Nest Depth in South American Species of Acromyrmex Leaf-Cutting Ants. Oecologia, 158, 165-175.

https://doi.org/10.1007/s00442-008-1113-Z

[37] Van Gils, H. and Vanderwoude, C. (2012) Leafcutter Ant (Atta sexdens) (Hymenoptera: Formicidae) Nest Distribution Responds to Canopy Removal and Changes in Micro-Climate in the Southern Colombian Amazon. Florida Entomologist, 95, 914-921. https://doi.org/10.1653/024.095.0414

[38] Ferji-Brener, A.G. and Ruggiero, A. (1994) Leaf-Cutting Ants (Atta and Acromyrmex) Inhabiting Argentina: Patterns in Species Richness and Geographical Range Sizes. Journal of Biogeography, 21, 391-399. https://doi.org/10.2307/2845757

[39] Jactel, H. and Brockerhoff, E.G. (2007) Tree Diversity Reduces Herbivory by Forest Insects. Ecology Letters, 10, 835-848.

https://doi.org/10.1111/j.1461-0248.2007.01073.x 
[40] Verza, S.S., Mussury, R.M., Camargo, R.S., Andrade, A.P.P. and Forti, L.C. (2017) Oviposition, Life Cycle, and Longevity of the Leaf-Cutting Ant Acromyrmex rugosus rugosus. Insects, 8, 80. https://doi.org/10.3390/insects8030080

[41] Silva, P., Bieber, A., Knoch, T., Tabarelli, M., Leal, I. and Wirth, R. (2013) Foraging in Highly Dynamic Environments: Leaf-Cutting Ants Adjust Foraging Trail Networks to Pioneer Plant Availability. Entomologia Experimentalis et Applicata, 147, 110-119. https://doi.org/10.1111/eea.12050 